Research article

\title{
Gluten-free diet may alleviate depressive and behavioural symptoms in adolescents with coeliac disease: a prospective follow-up case-series study
} Päivi A Pynnönen*1, Erkki T Isometsä², Matti A Verkasalo1,
Seppo A Kähkönen ${ }^{3}$, Ilkka Sipilä ${ }^{1}$, Erkki Savilahti ${ }^{1}$ and Veikko A Aalberg1

Address: ${ }^{1}$ Hospital for Children and Adolescents, Helsinki University Central Hospital, Helsinki, Finland, ${ }^{2}$ Department of Mental Health and Alcohol Research, National Public Health Institute, Helsinki, Finland and ${ }^{3}$ BioMag Laboratory, Engineering Center, Helsinki University Central Hospital, Cognitive Brain Research Unit, University of Helsinki, Helsinki, Finland

Email: Päivi A Pynnönen* - paivi.pynnonen@pp.fimnet.fi; Erkki T Isometsä - erkki.isometsa@ktl.fi; Matti A Verkasalo - matti.verkasalo@hus.fi; Seppo A Kähkönen - seppo.kahkonen@helsinki.fi; Ilkka Sipilä - ilkka.sipila@hus.fi; Erkki Savilahti - erkki.savilahti@hus.fi;

Veikko A Aalberg - veikko.aalberg@hus.fi

* Corresponding author

Published: 17 March 2005

BMC Psychiatry 2005, 5:14 doi:10.1186/147/-244X-5-14
Received: 15 November 2004

Accepted: 17 March 2005

This article is available from: http://www.biomedcentral.com/I47I-244X/5//4

(c) 2005 Pynnönen et al; licensee BioMed Central Ltd.

This is an Open Access article distributed under the terms of the Creative Commons Attribution License (http://creativecommons.org/licenses/by/2.0), which permits unrestricted use, distribution, and reproduction in any medium, provided the original work is properly cited.

\begin{abstract}
Background: Coeliac disease in adolescents has been associated with an increased prevalence of depressive and disruptive behavioural disorders, particularly in the phase before diet treatment. We studied the possible effects of a gluten-free diet on psychiatric symptoms, on hormonal status (prolactin, thyroidal function) and on large neutral amino acid serum concentrations in adolescents with coeliac disease commencing a gluten-free diet.
\end{abstract}

Methods: Nine adolescents with celiac disease, aged 12 to 16 years, were assessed using the semistructured K-SADS-Present and Lifetime Diagnostic interview and several symptom scales. Seven of them were followed at I to 2, 3, and 6 months on a gluten-free diet.

Results: Adolescent coeliac disease patients with depression had significantly lower pre-diet tryptophan/ competing amino-acid (CAA) ratios and free tryptophan concentrations, and significantly higher biopsy morning prolactin levels compared to those without depression. A significant decrease in psychiatric symptoms was found at 3 months on a gluten-free diet compared to patients' baseline condition, coinciding with significantly decreased coeliac disease activity and prolactin levels and with a significant increase in serum concentrations of CAAs.

Conclusion: Although our results of the amino acid analysis and prolactin levels in adolescents are only preliminary, they give support to previous findings on patients with coeliac disease, suggesting that serotonergic dysfunction due to impaired availability of tryptophan may play a role in vulnerability to depressive and behavioural disorders also among adolescents with untreated coeliac disease.

\section{Background}

Coeliac disease is an under-diagnosed autoimmune type of gastrointestinal disorder resulting from gluten ingestion in genetically susceptible individuals. Non-specific 
symptoms such as fatigue and dyspepsia are common, but the disease may also be clinically silent. Diagnosis is based on small-bowel biopsy, and a permanent gluten-free diet is the essential treatment. Undetected or neglected, coeliac disease is associated with serious complications. [1-3] Depressive symptoms $[4,5]$ and disorders [6] are common among adult patients with coeliac disease, and depressive and disruptive behavioural disorders are highly common also among adolescents, particularly in the phase before diet treatment [7]. Recently $73 \%$ of patients with untreated coeliac disease - but only $7 \%$ of patients adhering to a gluten-free diet - were reported to have cerebral blood flow abnormalities similar to those among patients with depressive disorders [8].

Improvement in state anxiety [5], in behavioural symptoms [9], and in depressive disorders [6,10] may occur after the start of a standard gluten-free diet, and after a vitamin B-6-supplemented gluten-free diet [11]. In some cases, however, the more serious depressive episodes have appeared following the commencement of a gluten-free diet [6]. Mechanisms involved have remained unclear. Some studies have suggested the possibility of impaired availability of tryptophan and disturbances in central serotonergic function as playing a role $[9,12]$. In parallel with this, a significant increase in major serotonin and dopamine metabolite concentrations in the brain has been reported after one year on a gluten-free diet [13].

The present work is a preliminary prospective psychiatric follow-up study of adolescents with newly diagnosed coeliac disease measuring psychiatric symptoms, hormonal status (prolactin, thyroidal function), and large neutral amino acid (LNAA) serum concentrations repeatedly after their commencement of a gluten-free diet, testing the hypothesis that the treatment of coeliac disease may increase the availability of tryptophan and alleviate psychiatric symptoms.

\section{Methods \\ Subjects}

The study sample comprised all nine adolescents (5 girls, 4 boys; aged $14.6 \pm 0.8$ ) consecutively diagnosed with coeliac disease between January 1999 and December 2000 in the Department of the Gastrointestinal Services of the Hospital for Children and Adolescents, Helsinki University Central Hospital, in Finland. None of the patients had a history of, or current psychiatric treatment. Duration of coeliac disease symptoms and signs (abdominal pain, diarrhoea, anaemia) leading to a biopsy was 2.3 ( \pm 1.5) years. The study was approved by the institutional Ethics Committee. Written informed consent was obtained from each patient and a parent.

\section{Evaluation}

Baseline psychiatric evaluation was conducted 1 to 4 weeks after the diagnostic biopsy, during the wait for the diagnosis of coeliac disease to be established by the pathologist. The adolescent and a parent were interviewed separately by an adolescent psychiatrist (PP) using a semistructured diagnostic interview, the Schedule for Affective Disorders and Schizophrenia for School-Age Children Present and Lifetime version (K-SADS-PL) [14]. Seven patients attended the follow-up visits with laboratory tests at $>1$ to $\leq 2,3$, and 6 months after starting a gluten-free diet (Table 1). Baseline and follow-up behavioural problems were assessed with the Youth Self Report (YSR) [15] and the Child Behavior Checklist (CBCL) [16], completed by a parent (Table 1), and depressive and anxiety symptoms by the 21-item versions of the Beck Depression Inventory (BDI) and Beck Anxiety Inventory (BAI), the 17 -item version of the Hamilton Depression Rating Scale (HAM-D), and the 14-item Hamilton Anxiety Rating Scale (HAM-A). CGAS (Children's Global Assessment) served as a part of the K-SADS-PL.

Coeliac disease activity was followed by determining serum tissue transglutaminase (S-tTGAbA) and endomysium (S-EndoAbA) autoantibodies [17]. Pre-diet blood samples for analysis of amino acids, prolactin, thyroid function [thyroxine (S-T4), thyroid-stimulating hormone (TSH)], vitamins B6 and B12, S-tTGAbA, and S-EndoAbA were obtained on the biopsy morning, and subsequent ones as a part of follow-up visits, both after overnight fasting, between 8 and 10 a.m. All nine patients had amino acid concentrations measured at baseline, and five of them during follow-up (1-2 times). A blood sample (2 $\mathrm{ml}$ ) was drawn from the ulnar vein into a vacuum tube for serum total and free L-tryptophan, and for other large neutral amino acids (LNAA). The tube was cooled immediately and stored refrigerated in ice until centrifuged. After centrifugation, the serum was frozen and stored at $20^{\circ} \mathrm{C}$ for 4 to 14 months (median 7.5 ) until its assay for the amino acids by a modified procedure described by Qureshi et al. [18]. All the samples were analysed in a single run, in Kuopio, Finland, and free and total L-tryptophan and other LNAA's were assessed as described by Tiihonen et al. [19].

\section{Statistical methods}

Statistical analysis was carried out with parametric and non-parametric tests as appropriate; tests for two-independent groups (T-test, Mann-Whitney U-test), for repeated measures of two-related groups (Wilcoxon signed-ranks test), for three-related groups (Friedman test) and Spearman's rank correlation testing were used. Pvalues (2-tailed) $<0.05$ were regarded as significant. 
Table I: Psychiatric symptoms and disease activity among adolescent $C D$ patients $(n=7$, mean \pm SD)

\begin{tabular}{|c|c|c|c|c|c|c|c|}
\hline & 0 (baseline) & I-2 months & P-valuel) & 3 months & P-valuel) & 6 months & P-value ${ }^{2)}$ \\
\hline CGAS 3) & $74.4( \pm 16.5)^{4)}$ & & & $86.9( \pm 5.6)$ & 0.043 & $88.3( \pm 9.2)$ & 0.006 \\
\hline HAM-D5) & $5.7( \pm 7.3)$ & & & $0.3( \pm 0.8)$ & 0.043 & $1.0( \pm 1.3)$ & 0.009 \\
\hline HAM-A') & $6.9( \pm 6.9)$ & & & $0.1( \pm 0.4)$ & 0.043 & $0.7( \pm 1.3)$ & 0.010 \\
\hline BDI7) & $3.4( \pm 6.5)$ & $\left.0.0( \pm 0.0)^{8}\right)$ & n.s. ${ }^{9)}$ & $0.1( \pm 0.4)$ & 0.041 & $0.6( \pm \mathrm{I} .1)$ & 0.014 \\
\hline$B A I^{\prime 0}$ & $3.0( \pm 2.9)$ & $1.3( \pm 1.5)^{8)}$ & n.s. & $0.7( \pm \mathrm{I} .1)$ & 0.042 & $1.4( \pm 2.2)$ & n.s. \\
\hline CBCL'I) Total problems & $28.3( \pm 12.8)$ & $18.4( \pm 6.9)$ & 0.028 & $14.0( \pm 9.5)$ & 0.028 & $18.4( \pm 16.2)$ & 0.007 \\
\hline Anxious/depressed & $3.9( \pm 3.1)$ & $\mathrm{I} .4( \pm \mathrm{I} .7)$ & 0.046 & $1.3( \pm 1.5)$ & 0.026 & $1.3( \pm 1.1)$ & 0.033 \\
\hline Aggressive behaviour & $7.3( \pm 4.2)$ & $5.6( \pm 2.2)$ & n.s. & $3.6( \pm 3.1)$ & 0.039 & $6.0( \pm 6.4)$ & 0.047 \\
\hline YSR I2) Total problems & $24.4( \pm 13.8)$ & $17.0( \pm 12.5)$ & n.s. & $8.0( \pm 7.8)$ & 0.018 & $9.4( \pm 7.4)$ & 0.001 \\
\hline Anxious/depressed & $2.7( \pm 3.4)$ & $1.6( \pm 2.2)$ & n.s. & $0.3( \pm 0.5)$ & 0.026 & $0.6( \pm 1.0)$ & 0.002 \\
\hline Aggressive behaviour & $5.1( \pm 2.7)$ & $4.1( \pm 2.7)$ & n.s. & $2.0( \pm 2.2)$ & 0.044 & $2.4( \pm 1.4)$ & 0.021 \\
\hline Somatic complains & $4.9( \pm 2.4)$ & $3.1( \pm 2.3)$ & 0.038 & $2.1( \pm 1.2)$ & 0.026 & $2.3( \pm 2.1)$ & 0.003 \\
\hline S-EndoAbA ${ }^{8)}$ & $\begin{array}{c}800(200- \\
1600)\end{array}$ & $200(5-400)$ & 0.018 & $5(5-1600)$ & 0.027 & $5(5-100)$ & 0.001 \\
\hline S-tTGAbA & $139( \pm 158)$ & $30( \pm 35)$ & 0.018 & $19( \pm 26)$ & 0.018 & $7( \pm 8)$ & $<0.001$ \\
\hline Prolactin $(\mathrm{mU} / \mathrm{l})^{13)}$ & $1569( \pm 767)$ & $218( \pm 60)$ & 0.028 & $284( \pm 170)$ & 0.018 & $205( \pm 92)^{14}$ & 0.019 \\
\hline S-T4/TSH (nmol/l:mU/l) & $34( \pm 6)$ & $64( \pm 38)^{14}$ & 0.043 & $84( \pm 53)$ & 0.043 & $74( \pm 32)^{15)}$ & 0.039 \\
\hline
\end{tabular}

1) non-parametric Wilcoxon signed-ranks test; compared with baseline; ${ }^{2)}$ repeated measures non-parametric Friedman test; 3) Children's Global Assessment; ${ }^{4)}$ mean \pm SD; 5) Hamilton Depression Rating Scale; 6) Hamilton Anxiety Rating Scale ; 7) Beck Depression Inventory; ${ }^{8}$ median (minmax); 9) non significant; ${ }^{10)}$ Beck Anxiety Inventory; ${ }^{11}$ ) Child Behavior Checklist; ${ }^{2}$ ) Youth Self Report; ${ }^{13)}$ normal: females 50-300, males 50-500; 14) $\mathrm{n}=6 ;{ }^{15)} \mathrm{n}=4$

\section{Results}

\section{Baseline evaluation}

At baseline, three adolescents $(3 / 9 ; 33 \%)$ had a depressive disorder: two girls had major depressive disorder (MDD), one with a learning disorder not otherwise specified (NOS), and another with comorbid conduct disorder; one girl had the depressive disorder NOS. Further, one boy had a phobic disorder plus attention-deficit hyperactivity disorder, and another conduct disorder NOS. Four adolescents (44\%) had no diagnosis.

Pre-diet free L-tryptophan was positively correlated with pre-diet levels of tTGAbA $(\mathrm{n}=8 ; \mathrm{r}=0.78, \mathrm{P}=0.022)$, and negatively with vitamin $\mathrm{B}-6(\mathrm{r}=0.73, \mathrm{P}=0.039)$ and $\mathrm{S}-\mathrm{T} 4$ $(\mathrm{r}=0.74, \mathrm{P}=0.035)$. Prolactin levels (Table 1$)$ from the biopsy morning showed a positive correlation with BDI score (self-report depression inventory; $\mathrm{r}=0.89, \mathrm{P}=$ $0.001)$, and a negative correlation with the ratio of L-tryptophan to amino acids competing for the same cerebral uptake mechanism (CAA) $(\mathrm{r}=0.68, \mathrm{P}=0.042)$, but not with free L-tryptophan levels. The sum of branched-chain amino acids (BCAA: valine, leucine, and isoleucine) showed no correlation with L-tryptophan or free L-tryptophan levels.

Depressive patients $(n=3 / 9)$ had significantly higher prediet prolactin levels (mU/l: mean \pm S.D. $=2450 \pm 676$ vs. $1194 \pm 598$, Mann-Whitney U-test, $\mathrm{P}=0.039)$ and prediet S-T4 levels (nmol/l: mean $102 \pm 3.1$ vs. $84 \pm 16.1$, Mann-Whitney U-test, $\mathrm{P}=0.024)$, and significantly lower
L-tryptophan/CAA ratios $(100 \times \mathrm{pmol} / \mu \mathrm{l}: \mathrm{pmol} / \mu \mathrm{l}:$ mean $10.0 \pm 0.2$ vs. $11.5 \pm 1.7$, Mann-Whitney U-test, $\mathrm{P}=0.020$ ) and free L-tryptophan concentrations (pmol $/ \mu \mathrm{l}$ : mean 4.7 \pm 0.5 vs. $8.4 \pm 3.0$, two-independent samples T-test, $\mathrm{P}=$ 0.029). Pre-diet free L-tryptophan correlated negatively with biopsy morning S-T4 level $(r=-0.74, P=0.035)$. No significant differences appeared in L-tryptophan (36.3 \pm 5.1 vs. $43.3 \pm 6.1$ ) or in L-tyrosine concentrations, nor in BCAA and CAA levels.

\section{Follow-up}

Two adolescents with conduct disorders, one a girl with concomitant MDD, did not adhere to the gluten-free diet and dropped out of the psychiatric follow-up. Among others $(n=7)$, a significant decrease in most of the problem and symptom scores of YSR and CBCL, and in BDI, BAI, and Hamilton scales was evident after 3 months on the gluten-free diet, compared to baseline (Table 1).

Celiac disease-associated antibody titres had decreased in all by the first month on a gluten-free diet, and had already normalised ( $=$ S-EndoAbA titre $<5$ and S-tTGAbA titre $<8$ ) in 4 of 7 patients by 6 months. Boys had lower biopsy morning prolactin levels (mU/l; mean 972, SD 450 vs. girls mean $2126 \pm 756$; one-way Anova $\mathrm{P}=0.032$ ), but higher levels after one month on the diet. In the first month, the S-T4/TSH ratio (nmol/l:mU/l) reflecting thyroid function increased significantly (Table 1 ). 
Table 2: Follow-up of the patients $(n=5)$ : psychiatric symptoms, CD activity, and amino acidconcentrations [median (min-max)].

\begin{tabular}{|c|c|c|c|c|c|}
\hline & 0 (baseline) & $\geq|<| .5$ months 1$)$ & P-value ${ }^{2)}$ & $\geq 3$ months & $\mathrm{P}$-value ${ }^{2)}$ \\
\hline CBCL Total problems & $34(9-39)$ & $21(8-29)$ & $* *$ & $21(2-22)$ & $* *$ \\
\hline YSR Total problems & $20(9-36)$ & $I \mid(5-4 I)$ & n.s. & $2(0-22)$ & $* *$ \\
\hline S-tTGAbA & $42(10-3 \mid 0)$ & $5(3-5 I)$ & ** & $3(1-17)$ & $* *$ \\
\hline Prolactin 3 ) & $1100(635-2850)$ & 256 (127-282) & n.s $*$ & $244(110-565)$ & $* *$ \\
\hline L-tyrosine ${ }^{4)}$ & $33(26-44)$ & $39(37-70)$ & n.s $*$ & $40(38-47)$ & $* *$ \\
\hline CAÁ $^{5)}$ & $353(3|6-44|)$ & 401 (368-657) & n.s $*$ & $395(367-568)$ & $* *$ \\
\hline L-tryptophan4) & $40(32-5 I)$ & $52(45-66)$ & n.s $*$ & $46(36-59)$ & n.s. \\
\hline Tryptophan/CAA $\left.{ }^{6}\right)$ & $11.3(10.1-14.9)$ & $12.0(10.1-14.1)$ & n.s. & $10.1(9.5-12.5)$ & n.s. \\
\hline Free L-tryptophan 4) & $4.9(4.5-11.8)$ & $8.4(5.3-10.9)$ & n.s $*$ & $10.6(5.0-19.0)$ & n.s. $* 7)$ \\
\hline Free tryptophan/CAA $\left.{ }^{6}\right)$ & $1.4(1.0-3.5)$ & $1.9(1.0-3.0)$ & n.s. & $2.6(1.3-3.4)$ & n.s. \\
\hline
\end{tabular}

I) amino acid concentrations; $\mathrm{n}=4$; ${ }^{2}$ Wilcoxon signed - ranks test: compared with baseline; $* *=P<0.05 ; *=P \geq 0.05<0.07 ;{ }^{3}$ ) $\mathrm{mU} / \mathrm{l}$; normal: females 50-300, males 50-500; 4) pmol/ $\mu \mathrm{l}$; 5) L-valine, L-leucine, L-isoleucine, L-phenylalanine, L-tyrosine; pmol/ $\mu \mathrm{l} ;{ }^{6}$ ) $100 \times \mathrm{pmol} / \mu \mathrm{l}$ : pmol/ $\mu \mathrm{l} ;{ }^{7}$ ) repeated Measures Friedman test, $n=4, P=0.050$

An initial increase in CAAs, also in tyrosine levels, and in total and free L-tryptophan was reaching significance after one month on a gluten-free diet. By 3 months, the increases in tyrosine alone and in CAAs as a group were significant, and the increase in free L-tryptophan was approaching significance (repeated measures Friedman test $\mathrm{n}=4$, Chi-Square 6,000, df 2, $\mathrm{P}=0.050$ ). (Table 2)

\section{Discussion}

We observed that the majority of adolescents with coeliac disease had depressive and behavioural symptoms before their diagnosis, and that coeliac disease patients with depression (all girls) had significantly lower pre-diet tryptophan/CAA ratios and free tryptophan concentrations and significantly higher biopsy morning prolactin levels. Adolescents with coeliac disease showed improvement in psychiatric symptoms after starting a gluten-free diet, and this improvement coincided with a significant decrease in coeliac disease activity and in prolactin levels, and with a significant increase in serum concentrations of L-tyrosine and other CAAs. The increase in free L-tryptophan levels was approaching significance. The findings of this study improvement in depressive and behavioural symptoms after the start of a gluten-free diet - are supported by the findings of our larger previous retrospective case-control study [7]. Although the results of the amino acid analysis and prolactin levels are only preliminary, they give support to the hypothesis that impaired availability of tryptophan and the possible consequent serotonergic dysfunction may play a role in vulnerability to depressive disorders among adolescents with untreated coeliac disease. A possible role for tyrosine and the brain's catecholamine metabolism (dopamine and noradrenaline) in these disorders cannot, however, be excluded.

The decrease observed in psychiatric symptoms took place regardless of the stress accompanying being diagnosed with a chronic and restrictive illness, and improvement was not explainable in terms of physical symptoms, since both in the present and in our previous study [7], the presence or alleviation of depression showed no association with somatic symptom severity. Our results from adolescents differ from those reported by Addolorato et al. [5]. In their follow-up study on adult patients with coeliac disease, a significant decrease in anxiety symptoms but not in depressive symptoms appeared after one year on a glutenfree diet. Although converging with the findings of Ljungman and Myrdal (20), the few symptoms of our adolescents with coeliac disease adhering to a gluten-free diet in our present and previous [7] studies are thus in contrast to the findings of depressive symptoms $[4,5]$ and disorders [6] as being common among adult patients with coeliac disease, even during diet treatment.

Since the free tryptophan and the tryptophan/CAA ratios in plasma determine the availability of tryptophan to the brain [21], our findings on depressive patients give preliminary support to suggestions of impaired availability of tryptophan as featuring in coeliac-associated depressive and behavioural disorders associated with celiac disease $[9,12,13]$. As we did not have a control group of healthy adolescents, we cannot say whether L-tryptophan or Ltyrosine levels or both are generally lower among adolescents with coeliac disease, as could be expected based on the findings of Hernanz and Polanco [9], who reported significantly decreased plasma tryptophan and tyrosine concentrations in untreated and treated children with coeliac disease compared to levels in controls.

In the present study, stress-induced biopsy-morning prolactin levels were significantly higher among depressive patients (all girls) and correlated negatively with L-tryptophan/CAA levels. This finding is only preliminary, but it is, however, interesting: Although disturbances in the cen- 
tral serotonergic system have been associated with depressive and impulse-control disorders among adults [see [22]], and children aged 6 to 12 years with a recent suicide attempt have shown lower whole blood tryptophan content [23], serotonergic dysfunction in adolescents with depression is still poorly studied. The prolactin hypersecretion response to the L-5-hydroxytryptophan challenge (L-5HTP) test reported among pre-pubertal girls with major depressive disorder [24] and among healthy children at high risk for major depressive disorder (= high family loading for major depression) [25], may be consistent with dysregulation of the central serotonergic system in childhood major depression [24]. Moreover, alterations in neuroendocrine responses to L-5HTP challenge tests, such as the prolactin hypersecretion and hyposecretion of cortisol found in healthy children, have been suggested to represent a trait marker for depression in children [25]. Thus, the high biopsy morning prolactin levels in depressed adolescents with untreated coeliac disease in the present study could be associated with serotonergic dysfunction. They could also be associated with dopaminergic dysfunction due to impaired availability of tyrosine, since dopamine is known to exert an inhibitory action on prolactin release in the hypothalamus [26]. In the present study, however, pre-diet prolactin levels did not correlate with tyrosine levels. Moreover, the function of the intestinal Catechol-O-Methyl Transferase enzyme (COMT) - known to play an important role in the peripheral O-methylation of catecholamines - remains unstudied in untreated coeliac disease. It is of some theoretical interest that reduced COMT activity in erythrocytes has at least once been associated with conditions such as primary affective disorders in women [27].

On the other hand, in the present study also nondepressed adolescents with coeliac disease had higher than normal biopsy morning prolactin levels. Significantly higher prolactin levels among untreated coeliac children (5-18 years) compared with treated patients has been reported by Reifen et al. [28]. They suggest that prolactin may play a part in the immune modulation of the intestine and could thus serve as a potential marker for coeliac disease activity.

Our preliminary findings on amino acid levels in adolescents with coeliac disease with or without depression are unlikely to be explained by malabsorption, since pre-diet free L-tryptophan and tryptophan ratios were not correlated with the BCAA levels that reflect the level of protein nutrition. It is of theoretical interest that increased production of interferon- $\gamma$ (IFN- $\gamma$ ), known to be the predominant cytokine produced by gluten-specific T-cells in active coeliac disease [29], can suppress serotonin function both directly and indirectly by enhancing tryptophan and serotonin turnover [30]. Increased IFN- $\gamma[30]$ and, for instance, such events as a stress-related increase in liver tryptophan pyrrolase enzyme activity [23], may lead to lowered tryptophan levels by the enhanced tryptophan catabolism induced by increased activity of the kynurenine-niacin pathway [30-32], even without malabsorption.

\section{Conclusion}

The alleviation of psychiatric symptoms found among adolescents with coeliac disease after commencement of a gluten-free diet coincides with a rapid decrease in antibody titres indicating coeliac disease activity and in their prolactin levels, and with a significant increase in L-tyrosine and other CAA serum concentrations, and with a nearly significant increase in the free fraction of L-tryptophan. Although these findings are only preliminary, and more research is needed, they give support to previous findings on patients with coeliac disease, suggesting that serotonergic dysfunction due to impaired availability of tryptophan may play a role in vulnerability to depressive and behavioural disorders, also among adolescents with untreated celiac disease. And since diet treatment may alleviate psychiatric symptoms, and earlier diagnosis may have beneficial effects on psychological and even on neurobiological vulnerability to depression, the possibility of psychiatric complications of coeliac disease needs to be taken into account in differential diagnosis of depressive and behavioural disorders.

\section{Declaration of competing interests}

The author(s) declare that they have no competing interests.

\section{Authors' contributions}

PAP, ETI, MAV, ES, VAA contributed to the conception and design of the study, and PAP, MAV, ES to acquisition of the data. All authors (PAP, ETI, MAV, SAK, IS, ES, VAA) contributed to the analysis and interpretation of the data, were involved in drafting and revising the article, and read and approved the final manuscript.

\section{Acknowledgements}

We thank Jyrki Liesivuori, MD, PhD, from the University of Kuopio, Finland for amino acid analysis, and Erkki Komulainen MA, PhD, for statistical advice. The study was supported by a grant from the Jalmari and Rauha Ahokas Foundation.

\section{References}

I. Holmes GKT: Non-malignant complications of coeliac disease. Acta Paediatr 1996:68-75.

2. Feighery C: Coeliac disease. B M J 1999, 3 I 9:236-239.

3. Mäki M, Mustalahti K, Kokkonen J, Kulmala P, Haapalahti M, Karttunen T, Ilonen J, Laurila K, Dahlbom I, Hansson T, Hopfl P, Knip M: Prevalence of Celiac Disease among Children in Finland. $N$ Eng J Med 2003, 348:25 I 7-2524.

4. Ciacci C, lavarone A, Mazzacca G, De Rosa A: Depressive Symptoms in Adult Coeliac Disease. Scand J Gastroenterol I998, 33:247-250. 
5. Addolorato G, Capristo E, Ghittoni G, Valeri C, Masciana' R, Ancona C, Gasbarrini G: Anxiety But Not Depression Decreases in Coeliac Patients After One-Year Gluten-free Diet: A Longitudinal Study. Scand J Gastroenterol 200I, 36:502-506.

6. Carta MG, Hardoy MC, Boi MF, Mariotti S, Carpiniello B, Usai P: Association between panic disorder, major depressive disorder and celiac disease. A possible role of thyroid autoimmunity. J Psychosomatic Res 2002, 53:789-793.

7. Pynnönen P, Isometsä E, Aronen E, Verkasalo M, Savilahti E, Aalberg $\checkmark$ : Mental disorders in adolescents with celiac disease. Psychosomatics 2004, 45:325-335.

8. Addolorato G, Di Giuda D, De Rossi G, Valenza V, Domenicali M, Caputo F, Gasbarrini A, Capristo E, Gasbarrini G: Regional Cerebral Hypoperfusion in Patients with Celiac Disease. Am J Med 2004, I 16:312-317.

9. Hernanz A, Polanco I: Plasma precursor amino acids of central nervous system monoamines in children with coeliac disease. Gut |99|, 32:|478-48|.

10. Corvaglia L, Catamo R, Pepe G, Lazzarri R, Corvaglia E: Depression in Adult Untreated Celiac Subjects: Diagnosis by the Pediatrician. Am / Gastroenterol 1999, 94:839-843.

II. Hallert C, Åström J, Walan A: Reversal of Psychopathology in Adult Coeliac Disease with the Aid of Pyridoxine (Vitamin B6). Scand J Gastroenterol 1983, I 8:299-304.

12. Hallert C, Mårtensson J, Allge'n L-G: Brain availability of monoamine precursors in adult coeliac disease. Scand J Gastroenterol 1982, 17:87-89.

13. Hallert C, Sedvall G: Improvement in central monoamine metabolism in adult coeliac patient starting a gluten-free diet. Psychol Med 1983, 13:267-271.

14. Kaufman J, Birmaher B, Brent D, Rao U, Flynn C, Moreci P, Williamson D, Ryan N: Schedule for Affective Disorders and Schizophrenia for School-Age Children-Present and Lifetime Version (K-SADS-PL): Initial Reliability and Validity Data. J Am Acad Child Adolesc Psychiatry 1997, 36:980-988.

15. Achenbach TM: Manual for the Youth Self-Report and 1991 Profile. Burlington:University of Vermont, Department of Psychiatry; 1991 .

16. Achenbach TM: Manual for the Child Behavior Checklist 4-18 and I99 I Profile. Burlington: University of Vermont, Department of Psychiatry; 1991.

17. Stern M: Comparative Evaluation of Serologic Tests for Celiac Disease: A European Initiative Toward Standardization. J Pediatr Gastroenterol Nutr 2000, 31:5 I3-5 I 9

18. Qureshi GA, Fohlin L, Bergström J: Application of high-performance liquid chromatography to the determination of free amino acids in physiological fluids. J Chromatogr A 1984, 297:91-100

19. Tiihonen J, Virkkunen M, Räsänen P, Pennanen S, Sainio E-L, Callaway J. Halonen , Liesivuori ]: Free L-tryptophan plasma levels in antisocial violent offenders. Psychopharmacology 200I, I57:395-400.

20. Ljungman G, Myrdal U: Compliance in teenagers with coeliac disease - a Swedish follow-up study. Acta Paediatr 1993, 82:235-238.

21. Bell C, Abrams J, Nutt D: Tryptophan depletion and its implications for psychiatry. Br J Psychiatry 200I, I 78:399-405.

22. Mann J: Role of Serotonergic System in the Pathogenesis of Major Depression and Suicidal Behavior. Neuropsychopharmacology 1999, 21:99-105.

23. Pfeffer CR, McBride PA, Anderson GM, Kakuma T, Fensterheim L, Khait V: Peripheral Serotonin Measures in Prepubertal Psychiatric Inpatients and Normal Children: Associations with Suicidal Behavior and Its Risk Factors. Biol Psychiatry 1998, 44:568-577.

24. Ryan ND, Birmaher B, Perel JM, Dahl RE, Meyer V, Al-Shabbout M, lyengar S, Puig-Antich J: Neuroendocrine Response to L-5Hydroxytryptophan Challenge in Prepubertal Major Depression. Arch Gen Psychiatry 1992, 49:843-85I.

25. Birmaher B, Kaufman J, Brent DA, Dahl RE, Perel JM, Al-Shabbout M, Nelson B, Stull S, Rao U, Waterman G, Scott MD, Williamson DE, Ryan ND: Neuroendocrine Response to 5-Hydroxy-L-Tryptophan in Prepubertal Children at High Risk of Major Depressive Disorder. Arch Gen Psych 1997, 54: I I I3-I I I9.

26. Harmer CJ, McTavish SFB, Clark L, Goodwin GM, Cowen PJ: Tyrosine depletion attenuates dopamine function in healthy volunteers. Psychopharmacology 200 I, I 54:105-III.
27. Guldberg HC, Mardsen CA: Catechol-O-Methyl Transferase: Pharmacological Aspects and Physiological Role. Pharmacological $\operatorname{Rev}$ 1975, 27: 174-193.

28. Reifen R, Buskila D, Maislos M, Press J, Lerner A: Serum prolactin in coeliac disease: a marker for disease activity. Arch Dis Child 1997, 77:155-157.

29. Sollid LM: Coeliac disease: dissecting a complex inflammatory disorder. Nat Rev Immunology 2002, 2:647-655.

30. Brown RR: Metabolism and biology of tryptophan. In Recent Advances in Tryptophan Research: Tryptophan and Serotonin Pathways Edited by: Fillippini GA, Costa CVL, Bertazzo A. Plenum, New York: Plenum; 1996:15-25.

31. Bonaccorso S, Meltzer H, Maes M: Psychological and behavioural effects of interferons. Curr Opin Psychiatry 2000, 13:673-677.

32. Menkes D, McDonald J: Interferon, serotonin and neurotoxicity. Psychol Med 2000, 30:259-268.

\section{Pre-publication history}

The pre-publication history for this paper can be accessed here:

\section{http://www.biomedcentral.com/1471-244X/5/14/pre} pub
Publish with Bio Med Central and every scientist can read your work free of charge

"BioMed Central will be the most significant development for disseminating the results of biomedical research in our lifetime. "

Sir Paul Nurse, Cancer Research UK

Your research papers will be:

- available free of charge to the entire biomedical community

- peer reviewed and published immediately upon acceptance

- cited in PubMed and archived on PubMed Central

- yours - you keep the copyright
BioMedcentral 